\title{
The Volkmann Ischemic Contracture of the Forearm is Preventable
}

\author{
Jurrian C. Reurings, Michiel H.J. Verhofstad ${ }^{1}$
}

\begin{abstract}
The acute compartment syndrome of the forearm is rare and may therefore be easily missed. Although many clinicians will not see such a patient during their entire career, profound knowledge of the symptoms is required to recognize the syndrome in time. Besides immediate identification of the compartment syndrome early surgical treatment is mandatory to avoid its devastating consequences. Then the functional results can be good, but if the correct diagnosis is missed a Volkmann's ischemic contracture will invariably develop. This paper aims to attend the reader to this diagnostic pitfall. Two patients with a compartment syndrome of the forearm are described to illustrate both ends of this diagnostic challenge. Pathophysiological, anatomical and clinical aspects, classification and therapeutic modalities are reviewed.
\end{abstract}

\section{Key Words \\ Volkmann's ischemic contracture $\cdot$ Compartment syndrome - Diagnosis - Treatment}

Eur J Trauma Emerg Surg 2007;33:539-44

DOI $10.1007 /$ s00068-007-6142-5

\section{Introduction}

The clinical appearance of the "Volkmann's ischemic contracture" has originally been described by Richard von Volkmann in 1881 [1]. Although the term "Volkmann's contracture" is sometimes incorrectly used for posttraumatic contractures in the lower leg [2,3], the classical location is the ventral compartment of the forearm [1]. It is the result of an acute compartment syndrome after severe soft tissue trauma including vascular injury, which is frequently, but not necessarily accompanied by a fracture. A compartment syndrome of the forearm is rare [4], and may therefore be missed in the acute phase, despite its specific clinical symptoms. If so, a Volkmann's contracture of the forearm develops. This leads to a life-long disability for the patient, huge economical consequences for the community and medico-legal affairs for the doctor.

\section{Patient A}

A 17-year-old motorcyclist collapsed into a truck and nearly drowned. Due to severe respiratory failure he was intubated and ventilated at the accident scene. After in-hospital screening bilateral lung injury and a complicated (Gustilo grade 2) multifragmental radius shaft fracture in his dominant right arm was diagnosed. All wounds were surgically closed and the fracture of the right forearm was stabilised with a non-circular cast. After 5 days of mechanical ventilation at the ICU, osteosynthesis of the forearm fracture was performed with an intramedullary Prevot-nail. A non-circular plaster cast was applied. Few hours after detubation the patient was extremely anxious and suffered from severe pain. His anxiety was attributed to the ICU period and treated with diazepam. The bandage covering the cast was cut and the cast was opened to allow soft tissues to swell and intravenous morphine and diclofenac were administered the entire evening and night. Despite large amounts of analgetics, the pain only slightly disappeared. Neurologic examination of the hand was not performed at this time. After 3 days, the sensory loss was diagnosed. When the first signs of a flexion contracture appeared, a Volkmann's contracture due to a missed compartment syndrome was suspected. Within a few weeks the patient developed a classical claw hand. An electromyogram (EMG) showed almost complete loss of motor and sensory function of all three forearm nerves. Fracture and wounds healed uncomplicated. After 2 months a flexor

${ }^{1}$ Division of Surgery, St. Elisabeth Hospital, Tilburg, The Netherlands.

Received: July 15, 2006; revision accepted: September 30, 2006; Published Online: May 15, 2007 
pronator slide operation and a release of the median nerve were performed. The flexion contracture relapsed despite intensive physiotherapy and nerve function of his dominant right forearm remained absent. The patient had to stop his education as an electro-mechanic and he was declared disabled for work at the age of 19 years.

\section{Patient B}

An 18-year-old female motorcyclist was hit by a car. After stabilisation in the emergency room an extraarticular unstable fracture of the right distal radius with luxation of the distal radio-ulnar joint and a bilateral mandibular fracture were diagnosed. The sensibility and arterial pulsations in the right hand were normal. There was significant contusion of the lower forearm. Open reduction and plate osteosynthesis of the radius (by a volar approach) and mandibular fractures were performed. Postoperatively a bandage smoothly pressuring the wound was applied. The pain in her forearm could adequately be treated by intravenous morphine. However, a few hours later the pain increased. The bandage was removed and the arm elevated. Physical examination was repeated 2 hours later, now the volar side of her forearm was very tense and median nerve function had disappeared. Passive stretch of the fingers increased pain. Based on these clinical findings a "compartment syndrome of the forearm" was diagnosed and immediate surgical exploration followed. Some hematoma was evacuated and a complete fasciotomy of the superficial and deep flexor compartments was performed. Especially the deep compartment appeared ischemic, but tissue reperfusion commenced immediately after fasciotomy. Tension free coverage of the median nerve and flexor tendons at the wrist could be achieved after a dorsal contra-incision. After operation she was free from pain and sensibility had fully recovered. Wounds and fractures healed uncomplicated. Wrist and hand function recovered completely. She was able to continue playing the piano on a semi-professional base.

Both cases show the typical presentation of a compartment syndrome of the forearm. If the doctor is not familiar with the symptoms, he erroneously treats pain with medication. Although pain is the main symptom, patients may have difficulties demonstrating this (e.g. due to decreased level of consciousness in case of brain injury or sedation). Also the use of postoperative regional anesthesia may mask the pain caused by a developing compartment syndrome [5]. Careful and repeated assessment for signs of a developing compartment syndrome in a limb is essential. The compartment syndrome of the forearm is rare [4], but it should be known and recognised early in order to give the patient the only right therapy, an adequate surgical decompression.

\section{Pathophysiology}

Volume expansion within a tissue compartment (e.g. due to hematoma or edema) is limited by the elasticity of surrounding structures. Rigid fascia allows only minimum volume expansion. Above a certain critical value, pressure instead of volume will increase. Tissue pressure normally varies between 0 and $8 \mathrm{mmHg}$ and capillary perfusion pressure between 30 and $40 \mathrm{mmHg}$. If tissue pressure reaches or exceeds the capillary perfusion pressure, microcirculation ceases and ischemia develops [6-8]. This state is known as a compartment syndrome. After acute surgical decompression damaged tissue will principally recover. However, after 6 hours of ischemia, substantial muscle necrosis develops [8]. Well differentiated myocytes are replaced by (myo-)fibroblasts, which tend to contract. In the forearm this results in the typical "claw hand" $[1,3,9]$. Peripheral nerves require less oxygen for their cell metabolism. Therefore, the consequences of nerve ischemia are longer reversible [8]. Nerve ischemia causes extreme pain. Sensibility decreases prior to motor function.

\section{Anatomical Aspects of the Forearm}

The forearm consists of a ventral and a dorsal part, divided by the interosseous membrane. The ventral part consists of a deep and a superficial flexor muscle compartment, the dorsal compartment contains the extensor muscles (Figure 1). All compartments are enveloped by rigid fascias. For three reasons the deep ventral compartment is most prone to a compartment syndrome. First, both forearm arteries run through the deep ventral compartment, making it more prone to high pressure bleedings. In case of a fracture, the hematoma will primarily develop here. Finally the deep ventral compartment has the smallest diameter and is therefore most susceptible to an increase of tissue pressure (Laplace's law). Since the median nerve resides between the deep flexor muscles, its loss of function is an early sign of a compartment syndrome.

\section{Clinical Signs and Diagnostic Tools Compartment Syndrome}

Accurate history taking and physical examination are the diagnostic keystones. The earliest sign of a compartment syndrome is extreme pain in the forearm [10]. 


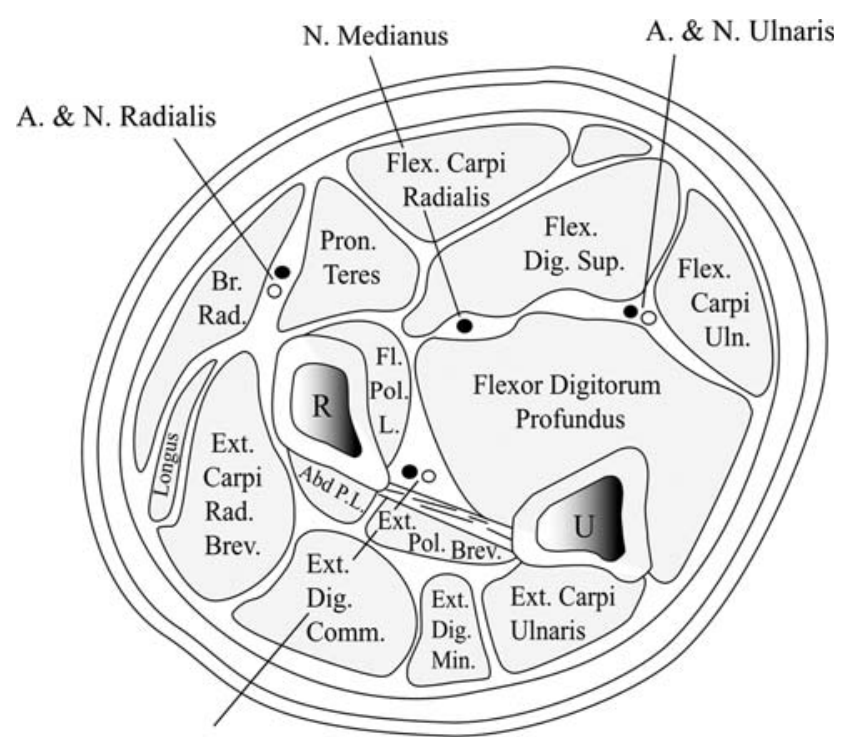

A. \& N. Interosseous Anterior

Figure 1. Cross section through the upper one-third of the forearm.

The muscle compartments of the forearm may feel tense. The hand may be warm and capillary refill can even be enhanced. Subsequently, the sensory function of the median nerve disappears and pain exceeds. Passive stretching of the fingers and wrist worsens pain, since it raises intra-compartmental pressure. Elevation of the arm decreases tissue perfusion and aggravates pain as well $[3,8,11]$. Pain progresses in time and hypoesthesia can extend to the entire hand. In the beginning the radial artery remains palpable. It only disappears in the final phase, when intracompartmental tissue pressure exceeds the arterial blood pressure. Therefore, an absent radial pulse is an absolute alarm sign [3]. Only in this final phase the hand is cold and capillary refill slow.

In situations where history taking and physical examination are unreliable, other diagnostic tools may be useful. For this purpose, pressure measurement devices are commercially available. Many different systems are used to measure intracompartmental pressure. The fluid-filled and the transducer-tipped catheter systems both have been shown to be useful in measuring intracompartmental pressure $[6,12,13]$. Studies to the accuracy of various fluid-filled catheter systems revealed that side-port needles are more accurate than straight needles [14]. A high tissue pressure proves the presence of a compartment syndrome, but values can be falsely low (e.g. needle not placed within the affected compartment or a tissue plug inside the needle). Although debate exists on the intracompartmental pressure that

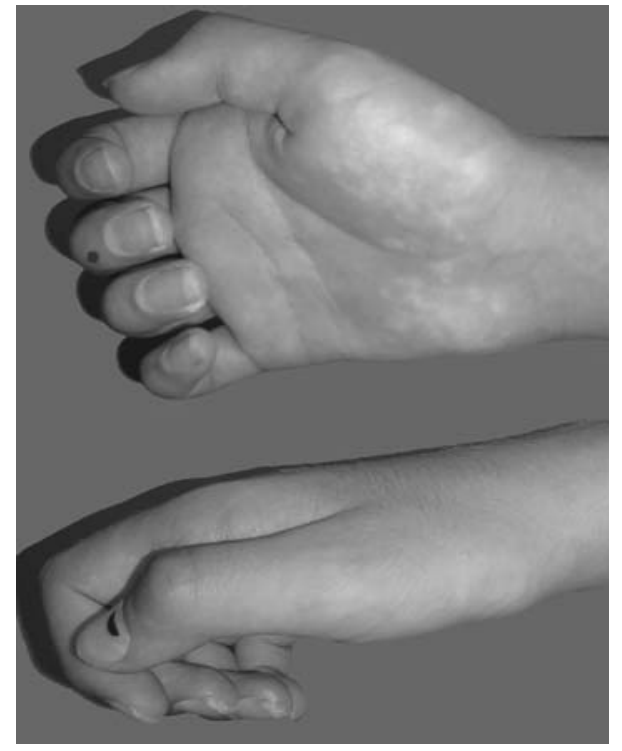

Figure 2. A classic example of a "claw hand". The MCP-joints are in neutral position, the PIP and DIP-joints are in flexion. The intrinsic hand muscles show signs of atrophy.

mandates fasciotomy, it must be seriously considered if pressures exceed $30 \mathrm{mmHg}[6,7,12]$. Another useful parameter is the difference between intracompartmental and diastolic blood pressure. When this difference is $<30 \mathrm{mmHg}$, fasciotomy is indicated [12, 15]. Measurement of serum lactate dehydrogenase and creatinin kinase may be helpful, but in the early phase of a compartment syndrome they are not increased [16]. A new and promising non-invasive technique is near infrared spectroscopy (NIRS). Tissue oxygenation instead of pressure is measured directly by transmitting light in the near infrared spectrum through the affected compartment. Since these wavelengths react differently with hemoglobin and oxyhemoglobin, the percentage tissue saturation can be calculated. Although this technique is promising, its reliability is still under investigation [17-20]. Finally, MR imaging with intravenous contrast can be helpful to estimate tissue perfusion in clinically ambiguous cases [20,21], but is not available in each hospital in the acute setting.

\section{Volkmann's Ischemic Contracture}

Also this diagnosis is mainly a clinical one. Depending on the severity and type of tissues involved in the compartment syndrome, patients present with various gradations of contracture. Tsuge classified the Volkmann's ischemic contracture of the forearm into three types [22]: mild, moderate and severe (Table 1). The mild type is usually caused by soft tissue injury alone, while the moderate and se- 
Table 1. Types of Volkmann's Ischemic contracture.

\begin{tabular}{llll}
\hline Type & Affected muscles & Neurological & Finger position \\
\hline Mild & m. flexor digitorum profundus & None or minimal loss of sensibility & Contracture of 2 or 3 fingers \\
Moderate & m. flexor digitorum profundus, m. flexor pollicis longus & Loss of sensibility of (parts of) the hand. & All fingers, the thumb and \\
& and parts of the superficial flexor muscles & The median nerve is affected predominantly & often the wrist are affected \\
Severe & All flexor muscles and parts of the extensor muscles & Serious loss of sensibility an motor function & Claw hand
\end{tabular}

vere contractures most often result from a fracture $[9,22]$. The classical and most severe presentation of a Volkmann's contracture is the "claw hand" $[1,9]$. It is characterised by interphalangeal flexion, metacarpophalangeal extension and wasting of intrinsic hand muscles (Figure 2). The role of MR imaging is unclear, but an EMG can be a valuable guide for the type of surgical treatment.

\section{Treatment \\ Compartment Syndrome}

In a patient with a suspected compartment syndrome, bandages should be removed immediately. Elevation of the arm should be avoided. It decreases perfusion pressure even more in contrast to tissue swelling from a simple edema or hematoma, where elevation relieves complaints $[3,8,11]$. Soon after the onset of symptoms an adequate fasciotomy using a curvilinear incision over the ventral aspect of the forearm and wrist should be performed (Figure 3). The fascias of both the superficial and deep compartment, including

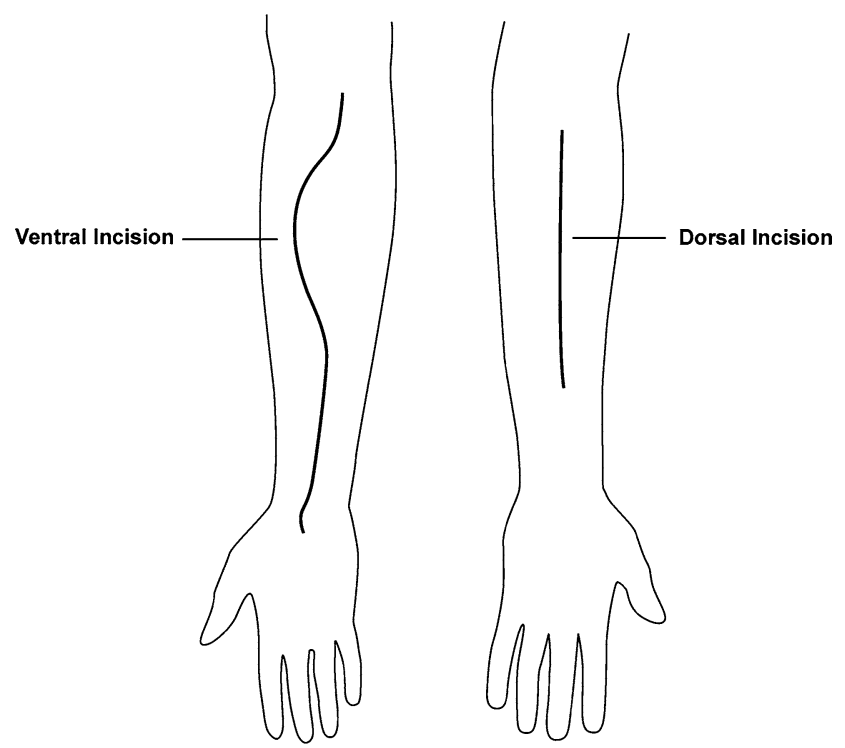

Figure 3. The position of the curvilinear ventral and dorsal incision in a forearm fasciotomy. individual fascias of affected flexor-muscles and carpal tunnel, should be opened [3, 23]. Pressure in the dorsal compartment may decrease due to a volar fasciotomy, but in case of doubt this compartment should be opened as well [23, 24]. Hereafter the microcirculation recovers immediately. Although tendons and nerves need to be protected from drying, primary wound closure is not indicated. A plaster cast should be applied to prevent contracture development.

\section{Volkmann's Ischemic Contracture}

Treatment options for an established contracture are limited and depend on its severity. The main treatment goals include pain reduction and improvement of motor and sensory function of wrist and hand.

\section{Conservative Therapy}

Nonoperative treatment mainly consists of prolonged physiotherapy, which aims to improve joint motion and muscle force $[9,11,22]$. Mild contractures can be treated by physiotherapy alone, but in moderate and severe types it is only supplementary to surgery.

\section{Surgical Treatment}

Various operative procedures have been described in the literature. They are complementary, rather than competitive. Therefore the surgeon's choice must depend on the specific problem of an individual patient. Surgical treatment is indicated in intermediate and severe contractures and in mild types not responding to conservative therapy.

Neurolysis aims to decompress damaged nerves. If performed within weeks after the onset of the symptoms, further loss of nerve function can be prevented [25-27]. Neurolysis is only rational if some nerve function is still present.

In a flexor pronator slide operation the contracted muscles are released from their proximal origin while the surgeon stretches fingers and hand [22, 28, 29]. Postoperatively the arm must be immobilised for 6 weeks in maximum extension. Often neurolysis is performed simultaneously [22, 27]. 
In a tendon-lengthening procedure, the tendon is cut distally at the wrist in a ' $Z$ '-shape. Subsequently, fingers and hand are placed in the correct position and the overlapping tendon parts are surgically reattached. In mild contractures this procedure is often sufficient to obtain a neutral position of hand and fingers $[26,27]$.

Tendon-transfers can be performed in cases where passive motion of wrist and fingers has been restored but active function remains insufficient. If the extensor compartment has not been affected by the compartment syndrome, tendons of these muscles are cut distally, transferred and re-attached to the nonfunctioning flexor tendons. This technique can only restore some flexion [30].

Innervated musculocutaneous flap transfers are a new technique for this indication. They must be considered experimental at this moment. Successful innervated free musculocutaneous flap transfers using a latissimus dorsi muscle flap have incidentally been described to restore finger flexion in patients with a severe Volkmann's contracture [31, 32].

In summary, the Volkmann ischemic contracture is a very disabilitating but preventable sequel of the compartment syndrome of the forearm. This syndrome is rare and may be diagnosed as easy as it is missed. Despite recent technical advances, clinical symptoms remain the cornerstones for a correct and fast diagnosis. Careful history taking, combined with accurate and repeated physical examination are essential. Every patient with severe pain after a traumatic or iatrogenic soft tissue injury, loss of sensibility and/or muscle function in forearm or hand, needs an emergency fasciotomy $[3,8,10,24]$. A delay in diagnosis and treatment will result in a Volkmann's ischemic contracture. Despite long and intensive physiotherapy and various restorative surgical techniques, the prognosis of a Volkmann's contracture remains poor.

\section{References}

1. von Volkmann R. Die ischaemischen Muskelähmungen und Kontrakturen. Zentralblatt Chir 1881;8:801-3.

2. Mubarak SJ, Carroll NC. Volkmann's contracture in children: aetiology and prevention. J Bone Joint Surg (Br) 1979;61:285-93.

3. Eaton RG, Green WT. Epimysiotomy and fasciotomy in the treatment of Volkmann's ischemic contracture. Orthop Clin North Am 1972;3:175-86.

4. Dente CJ, Feliciano DV, Rozycki GS, Cava RA, Ingram WL, Salomone JP, Nicholas JM, Kanakasundaram D, Ansley JP. A review of upper extremity fasciotomies in a level I trauma center. Am Surg 2004;70:1088-93.
5. Davis ET, Harris A, Keene D, Porter K, Manji M. The use of regional anaesthesia in patients at risk of acute compartment syndrome. Injury 2006;37:128-33.

6. Mubarak SJ, Owen CA, Hargens AR, Garetto LP, Akeson WH. Acute compartment syndromes: diagnosis and treatment with the aid of the wick catheter. J Bone Joint Surg (Am) 1978;60:1091-5.

7. Willy C, Sterk J, Volker HU, Sommer C, Weber F, Trentz O, Gerngross H. Das akute Kompartmentsyndrom. Ergebnisse einer klinisch-experimentellen Studie zu Druck- und Zeitgrenzwerten für die Notfallfasziotomie. Unfallchirurg 2001;104:381-91.

8. Matsen FA 3rd. Compartmental syndrome. An unified concept. Clin Orthop 1975;113:8-14.

9. Botte MJ, Keenan MA, Gelberman RH. Volkmann's ischemic contracture of the upper extremity. Hand Clin 1998; 14:483-97.

10. Holden CE. The pathology and prevention of Volkmann's ischaemic contracture. J Bone Joint Surg (Br) 1979;61:296-300.

11. Rau M, Lanz U. Die nichtoperative Behandlung der ischämischen Muskelkontraktur an Unterarm und Hand. Orthopäde 2003;32:397-401.

12. Whitesides TE, Haney TC, Morimoto K, Harada H. Tissue pressure measurements as a determinant for the need of fasciotomy. Clin Orthop 1975;113:43-51.

13. Willy C, Gerngross H, Sterk J. Measurement of intracompartmental pressure with use of a new electronic transducer-tipped catheter system. J Bone Joint Surg Am 1999;81:158-68.

14. Boody AR, Wongworawat MD. Accuracy in the measurement of compartment pressures: a comparison of three commonly used devices. J Bone Joint Surg Am 2005;87:2415-22.

15. McQueen MM, Court-Brown CM. Compartment monitoring in tibial fractures. The pressure threshold for decompression. J Bone Joint Surg (Br) 1996;78:99-104.

16. Ihedioha U, Sinha S, Campbell AC. Do creatine kinase (CK) levels influence the diagnosis or outcome in patients with compartment syndrome?. Scott Med J 2005;50:158-9.

17. Garr JL, Gentilello LM, Cole PA, Mock CN, Matsen FA 3rd. Monitoring for compartmental syndrome using near-infrared spectroscopy: a noninvasive, continuous, transcutaneous monitoring technique. J Trauma 1999;46:613-6.

18. Arbabi S, Brundage SI, Gentilello LM. Near-infrared spectroscopy: a potential method for continuous, transcutaneous monitoring for compartmental syndrome in critically injured patients. J Trauma 1999;47:829-33.

19. Gentilello LM, Sanzone A, Wang L, Liu PY, Robinson L. Nearinfrared spectroscopy versus compartment pressure for the diagnosis of lower extremity compartmental syndrome using electromyography-determined measurements of neuromuscular function. J Trauma 2001;51:1-8.

20. van den Brand JG, Nelson T, Verleisdonk EJ, van der Werken C. The diagnostic value of intracompartmental pressure measurement, magnetic resonance imaging, and near-infrared spectroscopy in chronic exertional compartment syndrome: a prospective study in 50 patients. Am J Sports Med 2005; 33:699-704.

21. Rominger MB, Lukosch CJ, Bachmann GF. MR imaging of compartment syndrome of the lower leg: a case control study. Eur Radiol 2004;14:1432-9.

22. Tsuge K. Treatment of established Volkmann's contracture. J Bone Joint Surg (Am) 1975;57:925-9. 
23. Gelberman RH, Zakaib GS, Mubarak SJ, Hargens AR, Akeson WH. Decompression of forearm compartment syndromes. Clin Orthop 1978;134:225-9.

24. Gelberman RH, Garfin SR, Hergenroeder PT, Mubarak SJ, Menon J. Compartment syndromes of the forearm: diagnosis and treatment. Clin Orthop 1981;161:252-61.

25. Chuang DC, Carver N, Wei FC. A new strategy to prevent the sequelae of severe Volkmann's ischemia. Plast Reconstr Surg 1996;98:1023-31.

26. Seddon HJ. Volkmann's contracture - treatment by excision of the infarct. J Bone Joint Surg 1956;38:152-74.

27. Sundararaj GD, Mani K. Management of Volkmann's ischaemic contracture of the upper limb. J Hand Surg (Br) 1985;10:401-3.

28. Page $C M$. Operation for the relief of flexion-contracture in the forearm. J Bone Joint Surg 1923;5:233-4.

29. Scaglietti $O$. Sindromi cliniche immediate e tardive de lesione vascolari nelle fratture degli arti. Riforma Medica 1957;71:749-55.

30. Sabapathy SR, Gowda DK, Ranade AB, Venkatramani H, Sebastin SJ. Functional outcome of extensor carpi radialis longus transfer for finger flexion in posttraumatic flexor muscle loss. J Hand Surg [Am] 2005;30:267-72.
31. Ortak $T$, Uraloglu $M$, Orbay $H$, Tekin $F$, Unlu RE, Sensoz O. Transfer of innervated split latissimus dorsi free musculocutaneous flap for flexion and extension of the fingers. Ann Plast Surg 2006;56:443-6.

32. Gousheh J, Arab H, Gilbert A. The extended latissimus dorsi muscle island flap for flexion or extension of the fingers. J Hand Surg $[\mathrm{Br}]$ 2000;25:160-5.

\section{Address for Correspondence}

Michiel H.J. Verhofstad, MD, PhD

Division of Surgery

St. Elisabeth Hospital

PO Box 90151

5000 LC

Tilburg

The Netherlands

Phone $(+31 / 13) 5391313$

e-mail: m.verhofstad@elisabeth.nl 